\title{
Modeling the Effect of Crude Oil Impacted Sand on the Properties of Concrete Using Artificial Neural Networks
}

\author{
W. O. Ajagbe, ${ }^{1}$ A. A. Ganiyu, ${ }^{2}$ M. O. Owoyele, ${ }^{1}$ and J. O. Labiran ${ }^{3}$ \\ ${ }^{1}$ Department of Civil Engineering, University of Ibadan, Ibadan, Nigeria \\ ${ }^{2}$ Department of Civil and Environmental Engineering, Kwara State University, Malete, PMB 1530, Ilorin, Kwara State, Nigeria \\ ${ }^{3}$ Segun Labiran and Associates, P.O. Box 6289 Agodi, Ibadan, Nigeria
}

Correspondence should be addressed to A. A. Ganiyu; abideen.ganiyu@kwasu.edu.ng

Received 11 March 2013; Accepted 13 April 2013

Academic Editors: P. J. S. Cruz and H.-L. Luo

Copyright (C) 2013 W. O. Ajagbe et al. This is an open access article distributed under the Creative Commons Attribution License, which permits unrestricted use, distribution, and reproduction in any medium, provided the original work is properly cited.

\begin{abstract}
A network of the feedforward-type artificial neural networks (ANNs) was used to predict the compressive strength of concrete made from crude oil contaminated soil samples at $3,7,14,28,56,84$, and 168 days at different degrees of contamination of $2.5 \%$, $5 \%, 10 \%, 15 \%, 20 \%$ and $25 \%$. A total of 49 samples were used in the training, testing, and prediction phase of the modeling in the ratio $32: 11: 7$. The TANH activation function was used and the maximum number of iterations was limited to 20,000 the model used a momentum of 0.6 and a learning rate of 0.031056 . Twenty (20) different architectures were considered and the most suitable one was the 2-2-1. Statistical analysis of the output of the network was carried out and the correlation coefficient of the training and testing data is 0.9955712 and 0.980097 . The result of the network has shown that the use of neural networks is effective in the prediction of the compressive strength of concrete made from crude oil impacted sand.
\end{abstract}

\section{Introduction}

Concrete is unarguably the commonest material used in the construction of civil engineering structures; it is a mixture of cement, aggregates (fine and coarse), and water. The slurry (i.e., the cement and water) binds the aggregates to a hard mass; the paste hardens because of the hydration (i.e., the chemical reaction of the cement and water). It is a versatile construction material adaptable for different uses. Depending on the requirements demanded by the engineer, several other materials like admixture and additives can be added to alter the properties of the concrete in order to yield the expected result.

The increase in demand for crude oil as a source of energy and as a primary raw material for industries has resulted in an increase in its production, transportation, and refining which in turn has resulted in gross pollution of the environment. Oil pollution occurs when crude oil is introduced into the environment directly or indirectly by man's activities resulting in an unfavourable change in such a way that the safety and welfare of any living organism are endangered.
The principal causes of oil pollution in the world include poor designs of ships and terminals, mechanical failure, operation procedures, human error, oil well blowout, and transportation. Other causes of oil spillage in Nigeria arise from corrosion of pipelines and tankers and sabotage [1].

Due to this occurrence of spillage, the sand of the environment gets contaminated with crude oil. It is this contaminated sand that is used in the making of concrete to erect structures in the neighborhood or may be used as borrowed material to other sites. The degree of contamination affects the strength of the concrete made from the sand; the extent of such alteration can only be known by experiment. The properties of concrete that are affected due to contamination from crude oil may include its flexural strength, compressive strength, durability, slump, compacting factor, water absorption, linear shrinkage, surface resistivity, and fire resistance [2].

Concrete strength cannot be measured prior to it being placed; it gains strength over a long period of time after pouring, the characteristic strength of which is defined as its compressive strength at 28 days. In quality control of concrete, the compressive strength of concrete is considered 
the most important property and it is used to determine its strength [3-5]. Interestingly, neither waiting for 28 days would serve the rapidity of construction, nor will neglecting it serve the quality control process on concrete in large construction sites. Therefore, rapid and reliable prediction for the strength of concrete would be of great significance. The compressive strength of concrete is affected by water cement ratio, volume of entrained air, type of cement, curing conditions, presence of additives and admixtures, and aggregate characteristics like size, shape, surface texture, grading, and mineralogy [6].

Artificial Intelligence is the study of intelligent agents, where an intelligent agent is a system that perceives its environment and takes action that maximizes its chances of success [7]. Artificial neural networks (ANNs) have been developed as generalizations of mathematical models of biological nervous systems. It imitates a human brains learning capabilities. In other words, an artificial neuron is a mathematical function conceived as a simple model of a real biological neuron. It needs sufficient input-output data and it can continuously retrain new data to adapt it conveniently $[8,9]$.

ANN has been used to solve problems involving incomplete information and has been applied to numerous civil engineering problems like prediction of settlement of shallow foundations, new methods of concrete mix design, modeling of slump of concrete, strength properties of highperformance concrete, construction duration of buildings, modeling soil behavior, settlement of structures, slope stability, water demand, and so forth [10-15]. In particular, ANN was used in $[16,17]$ to predict the behavior of different constituents of concrete mixture to obtain the compressive strength of concrete while [18] proposed a mathematical model capable of predicting the effect of mixture matrix to produce the required concrete compressive strength.

\section{Methodology}

2.1. Modeling Tool and Data Used. The neural network application used was the free access version of the Qnet 2000 modeling tool. Qnet is a backpropagation neural modeling system that is designed to exploit the ever increasing power of the computer hardware and operating systems. Qnet is able to predict based on the artificial input vector set in by the modeler the compressive strength of concrete used in its training. Result of the past experiment reported in [5] was used in the training and testing the Qnet tool. The data set contains 49 samples in all; it shows the result obtained from casting concrete with different proportions of crude oil contamination ranging from $2.5-25 \%$ within the period of 3-168 days.

In the experiment, soil samples were obtained from three different crude oil contaminated sites, namely, Bomu, BDere, and Bodo city of Gokana LGA of Cross Rivers State in Nigeria. The total petroleum hydrocarbon (TPH) in the samples was determined using gravimetry, following saponification in methanolic $\mathrm{KOH}$, extraction by $\mathrm{n}$-Hexane, and separation via liquid chromatography, to know the crude oil percentages in the contaminated sand samples. In addition, the particle size distribution of the residual dry sands was carried out to serve as guide for the choice of sand for the main experiment.

Fresh uncontaminated sand similar in grade to sands of the contaminated sites was contaminated with crude oil at $2.5 \%, 5 \%, 10 \%, 15 \%, 20 \%$, and $25 \%$ by the weight of sand. The resulting COIS was air-dried for about five days to allow proper reaction of the mixture and simulate the oil spill environment. The COIS was used to produce concrete cubes with a mix ratio $1: 1.8: 2.7$ at water cement ratio of 0.5 using the British method of concrete design [19]. The filling of the mould was in three layers and as manually compacted using $16 \mathrm{~mm}$ diameter metal rod at 25 strokes per layer [20]. Following this, 147 concrete cubes comprised of 21 controls and 126 crude oil contaminated specimens were produced. The cubes $100 \times 100 \times 100 \mathrm{~mm}$ were demoulded after 24 hours of casting and cured in a water tank [21].

The compressive strength gained was observed at ages $3,7,14,28,56,84$, and 168 days [22], the values of which were utilized for the present work. COIS concrete samples showed slow rate of strength gain and strength reduction compared with the control samples. The reduction of compressive strength of concrete by the presence of COIS is a function of the concentration of the crude oil in the sand; the higher the concentration, the higher the strength reduction. An $18 \%-90 \%$ compressive strength was lost due to $2.5 \%-25 \%$ crude oil contamination, respectively.

2.2. Training Process. The data set used for this model was divided into 3 categories, namely, the training, testing, and predicting set in the following proportion: $32: 11: 7$. The testing data were randomly chosen by Qnet though the number was specified. The training procedure was carried out by presenting the network with the set of experimental data in the patterned format. Each training pattern included an input of a set of two parameters representing days and degree of contamination and an output set contains the compressive strength. The network is presented with the variable in the input vector of the first training pattern, followed by an appropriate computation through the nodes in the hidden layers and prediction of the appropriate outputs. The error between the predicted and target values is calculated and stored. The network is then presented with the second training pattern and so on until the network has gone through all the data available for the network.

The root mean square (RMS) error is then calculated and backpropagated to the network. Biases and weights (the connection strength) between nodes are modified during the backpropagation phase such that the RMS is reduced. The process of the introduction of training input-output pairs to the network, calculation of the RMS error, and finally the adjustment of weights and biases to reduce the RMS error is one iteration. This process continues until convergence is achieved or the maximum number of iterations is reached. The training ANN model is represented by the connection weights once the previous procedure is converged.

2.3. Network Architecture. The architecture selected for use is the 2-2-1 network meaning that there are two input nodes 
TABLE 1: Modeling data.

\begin{tabular}{|c|c|c|c|c|c|c|c|c|}
\hline \multirow{3}{*}{ S/No. } & \multirow{3}{*}{ Age (days) } & \multicolumn{7}{|c|}{ Crude oil content (\%) } \\
\hline & & Control & 2.5 & 5 & 10 & 15 & 20 & 25 \\
\hline & & \multicolumn{7}{|c|}{ Compressive strength $\left(\mathrm{N} / \mathrm{mm}^{2}\right)$} \\
\hline 1 & 3 & 14.50 & 11.00 & 8.17 & 5.00 & 0.83 & 1.83 & 0.83 \\
\hline 2 & 7 & 21.25 & 17.00 & 13.17 & 8.50 & 3.00 & 3.00 & 1.83 \\
\hline 3 & 14 & 25.50 & 21.50 & 13.83 & 9.50 & 5.17 & 3.83 & 2.17 \\
\hline 4 & 28 & 31.50 & 23.50 & 18.33 & 12.83 & 6.61 & 5.00 & 3.50 \\
\hline 5 & 56 & 33.50 & 27.33 & 21.50 & 13.83 & 7.33 & 7.33 & 4.00 \\
\hline 6 & 84 & 33.50 & 31.25 & 21.67 & 15.67 & 8.33 & 7.83 & 5.33 \\
\hline 7 & 168 & 40.30 & 33.00 & 24.30 & 19.00 & 11.90 & 8.80 & 5.50 \\
\hline
\end{tabular}

TABLE 2: Details of various architectures examined.

\begin{tabular}{|c|c|c|c|c|c|c|c|}
\hline $\mathrm{N}$ & $\mathrm{ARCH}$ & L.R & $\mathrm{M}$ & Activation funct. & R.M.S.E TR. & R.M.S.E TE. & IT \\
\hline N1 & $2-2-1$ & 0.01000 & 0.8 & SIG-SIG-SIG & 0.054328 & 0.033530 & 10000 \\
\hline $\mathrm{N} 2$ & $2-2-1$ & 0.01000 & 0.8 & TANH-TANH-TANH & 0.029904 & 0.024476 & 10000 \\
\hline N3 & $2-2-1$ & 0.01000 & 0.8 & SIG-TANH-SIG & 0.034249 & 0.025659 & 10000 \\
\hline N4 & $2-2-1$ & 0.01000 & 0.8 & TANH-SIG-TANH & 0.022480 & 0.020762 & 10000 \\
\hline N5 & $2-2-1$ & 0.05513 & 0.8 & TANH-TANH-TANH & 0.021212 & 0.020793 & 10000 \\
\hline N6 & $2-2-1$ & 0.11000 & 0.8 & TANH-TANH-TANH & 0.019380 & 0.021277 & 20000 \\
\hline N7 & $2-2-1$ & 0.10450 & 0.8 & SIG-SIG-SIG & 0.023245 & 0.021244 & 20000 \\
\hline N8 & $2-3-1$ & 0.09928 & 0.8 & TANH-TANH-TANH & 0.016828 & 0.021612 & 20000 \\
\hline N9 & $2-3-1$ & 0.09431 & 0.8 & SIG-SIG-SIG & 0.022184 & 0.022319 & 20000 \\
\hline N10 & $2-3-1$ & 0.09928 & 0.8 & SIG-SIG-SIG & 0.017338 & 0.021098 & 20000 \\
\hline N11 & $2-3-1$ & 0.09929 & 0.8 & TANH-TANH-TANH & 0.015696 & 0.027982 & 20000 \\
\hline $\mathrm{N} 12$ & $2-4-1$ & 0.06464 & 0.8 & TANH-TANH-TANH & 0.014510 & 0.026469 & 20000 \\
\hline N13 & $2-4-1$ & 0.06141 & 0.8 & SIG-SIG-SIG & 0.015890 & 0.026524 & 20000 \\
\hline N14 & $2-5-1$ & 0.09500 & 0.6 & TANH-TANH-TANH & 0.014924 & 0.026600 & 20000 \\
\hline N15 & $2-6-1$ & 0.09500 & 0.6 & SIG-SIG-SIG & 0.0199275 & 0.020644 & 20000 \\
\hline N16 & $2-6-1$ & 0.06500 & 0.6 & TANH-TANH-TANH & 0.012363 & 0.027681 & 20000 \\
\hline N17 & $2-2-2-1$ & 0.03000 & 0.6 & TANH-TANH-TANH & 0.021810 & 0.020928 & 20000 \\
\hline N18 & $2-2-2-1$ & 0.95000 & 0.6 & SIG-SIG-SIG & 0.021958 & 0.021007 & 20000 \\
\hline N19 & $2-2-4-1$ & 0.03033 & 0.6 & TANH-TANH-TANH & 0.020828 & 0.020437 & 20000 \\
\hline $\mathrm{N} 20$ & $2-2-1$ & 0.03106 & 0.6 & TANH-TANH-TANH & 0.016831 & 0.036802 & 20000 \\
\hline
\end{tabular}

$\mathrm{N}$ : network number; ARCH: network architecture; L.R: learning rate; M: momentum.

R.M.S.E TR.: root mean square error for training data.

R.M.S.E TE.: root mean square error for testing data.

IT: maximum number of iterations.

representing days and degree of contamination, two nodes at the hidden layer, and one output layer representing the compressive strength. The selected activated function for the network is the TANH function due to its better performance when compared with the sigmoid function. The maximum number of iterations used was 20,000 with a momentum of 0.6 and the learning rate of 0.031056 . Table 1 shows the modeling data; the mix ratio of the concrete result used was $1: 1.8: 2.7$ for cement, sand, and granite, respectively, with a water-cement ratio of 0.5 .

\section{Results and Discussion}

3.1. Evaluation of Network Architecture. The modeling tool Qnet was used to consider different architectures. Twenty
(20) different architectures were considered and their details are given in Table 2 .

3.2. Network Output. The result of the selected architecture is given in Table 3; the table compares the predicted result with the experimental result of the testing and the validating data set. The maximum difference between the experimental and the predicted value is $5.50 \mathrm{~N} / \mathrm{mm}^{2}$. The RMS error of the training and testing set is a reflection of how suitable the network is for prediction. The trained network was used to predict 7 new data that were not introduced to the network during the training phase.

Figure 1 shows a graph of the RMS error of the training set against the number of iterations; it can be seen from the graph that the RMS error decreases with an increase in the number 


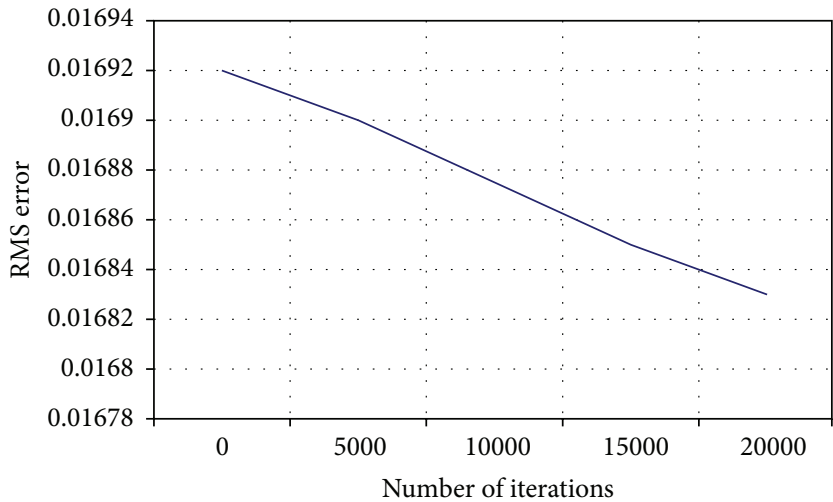

(a)

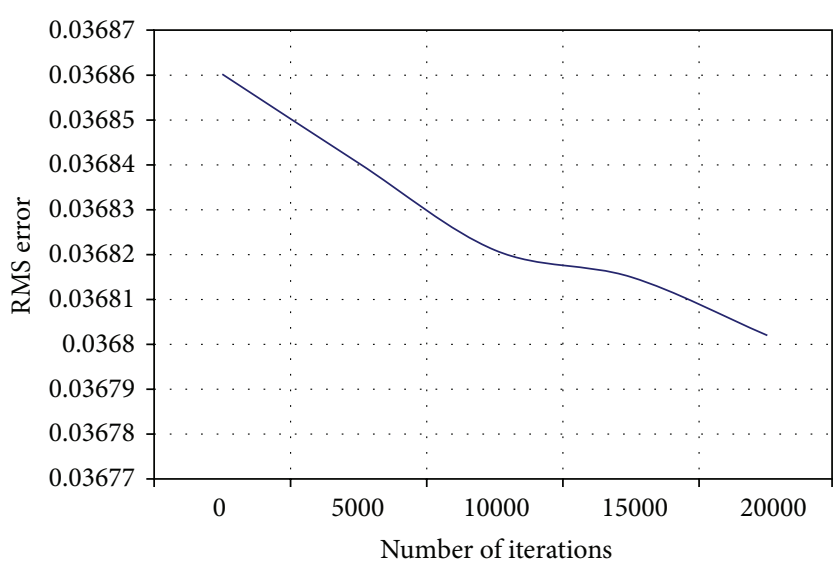

(b)

FIgURE 1: (a-b) A plot of the RMS error against number of iterations for training and testing set.

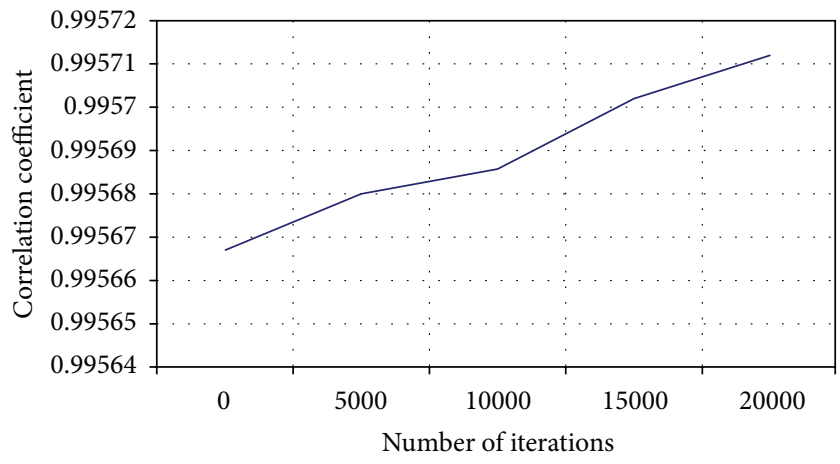

(a)

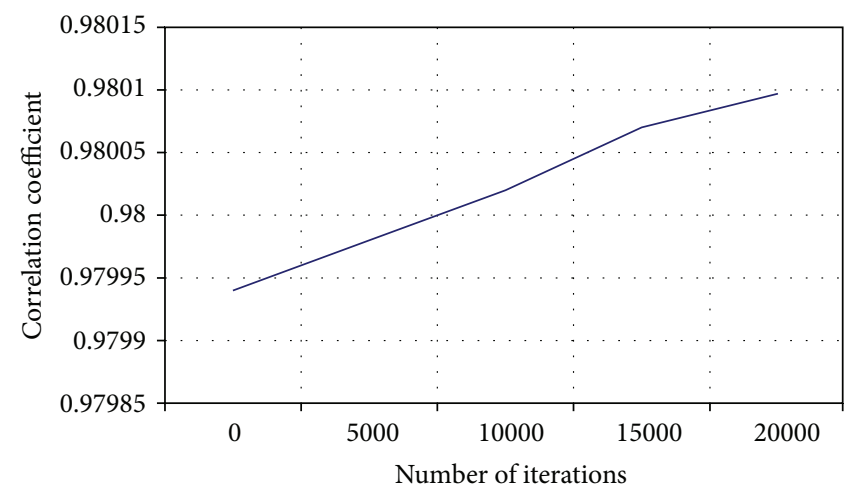

(b)

Figure 2: (a-b) A plot of correlation coefficients against iterations for training and testing set.

TABLE 3: Network results.

\begin{tabular}{lccc}
\hline Days & $\begin{array}{c}\text { Contamination } \\
(\%)\end{array}$ & $\begin{array}{c}\text { Experimental strength } \\
\left(\mathrm{KN} / \mathrm{m}^{2}\right)\end{array}$ & $\begin{array}{c}\text { Predicted strength } \\
\left(\mathrm{KN} / \mathrm{m}^{2}\right)\end{array}$ \\
\hline 3 & 20 & 1.83 & 1.95949 \\
7 & 0 & 21.25 & 19.65660 \\
7 & 5 & 13.17 & 11.59376 \\
7 & 20 & 3.00 & 2.96281 \\
14 & 15 & 5.17 & 6.08069 \\
28 & 0 & 31.50 & 29.46312 \\
28 & 20 & 5 & 5.49207 \\
28 & 25 & 3.50 & 4.09650 \\
84 & 5 & 21.67 & 24.11810 \\
168 & 5 & 24.30 & 29.80714 \\
168 & 15 & 11.90 & 12.54894 \\
$3^{*}$ & 5 & 8.17 & 8.72138 \\
$7^{*}$ & 25 & 1.83 & 2.25217 \\
$14^{*}$ & 0 & 25.50 & 24.62380 \\
$28^{*}$ & 15 & 6.61 & 7.91919 \\
$56^{*}$ & 25 & 4.00 & 4.64828 \\
$84^{*}$ & 10 & 15.67 & 15.46192 \\
$168^{*}$ & 2.5 & 33.00 & 35.17997 \\
\hline
\end{tabular}

${ }^{*}$ Shows the validating sets. of iterations. If the training continues, the error approaches a minimum/steady value. Further training of the network will lead to what is known as overtraining; local minima are said to have occurred when the network gets into this trap. The same explanation holds for the test data.

The correlation coefficient (Figure 2) is an indication of the level of agreement or disagreement between experimental result and the predicted result. The value ranges between 0 and 1 ; a value close to reflects a good agreement or disagreement. From the statistics shown, it can be seen that the correlation of the training and testing data is 0.9955712 and 0.980097, respectively, thus showing that there exists a good agreement between the expected and the predicted values.

\section{Conclusion and Recommendations}

This project presents a nontraditional approach to the determination of the predictive strength of concrete through the use of the artificial neural networks. It demonstrates the ability of feedforward backpropagation neural networks to predict with an acceptable level of accuracy from the data 
sets introduced to the network. Although the number of data sets available for modeling particular training and testing the network as minimal, the network is able to predict effectively the compressive strength of concrete made from crude oil contaminated soil samples. The model can be improved upon by increasing the data sets for the training and testing phase to cover more range of days and degree of contamination. In addition, the next line of action might be towards developing model equations that will enable the user to predict without the actual involvement of the computer.

\section{References}

[1] O. T. Badejo and P. C. Nwilo, Management of Oil Spill Dispersal Along the Coastal Areas, Department of Surveying and Geoinformatics, University of Lagos, Lagos, Nigeria, 2004.

[2] W. O. Ajagbe, O. A. Agbede, and B. I. O. Dahunsi, "Effect of crude oil impacted sand on the properties of concrete," in Proceedings of the 4th West Africa Built Environment Research (WABER '12), S. Laryea, S. A. Agyepong, R. Leiringer, and W. Hughes, Eds., pp. 177-189, Abuja, Nigeria, 2012.

[3] R. Gupta, M. A. Kewalramani, and A. Goel, "Prediction of concrete strength using neural-expert system," Journal of Materials in Civil Engineering, vol. 18, no. 3, pp. 462-466, 2006.

[4] G. M. Ayininuola, "Influence of diesel oil and bitumen on compressive strength of concrete," Journal of Civil Engineering, vol. 37, no. 1, pp. 65-71, 2009.

[5] W. O. Ajagbe, O. O. Omokehinde, G. A. Alade, and O. A. Agbede, "Effect of Crude Oil impacted sand on compressive strength of concrete," Construction and Building Materials, vol. 26, no. 1, pp. 9-12, 2012.

[6] K. Janković, D. Nikolić, D. Bojović, L. Lončar, and Z. Romakov, "The estimation of compressive strength of normal and recycled aggregate concrete," Architecture and Civil Engineering, vol. 9, no. 3, pp. 419-431, 2011.

[7] B. Krose and P. V. D. Smagt, Introduction to Neural Networks, Faculty of Mathematics and Computer Science, University of Amsterdam, Amsterdam, The Netherlands, 1996.

[8] M. Chakraborty, "Artificial neural network for performance modeling and optimization of CMOS analog circuits," International Journal of Computer Applications, vol. 58, no. 18, pp. 6-12, 2012.

[9] I. C. Yeh, "Exploring concrete slump model using artificial neural networks," Journal of Computing in Civil Engineering, vol. 20, no. 3, pp. 217-221, 2006.

[10] S. Bhoka and S. O. Ogunlana, "Application of artificial neural network to forecast construction duration of buildings at the predesign stage," Engineering, Construction and Architectural Management, vol. 6, no. 2, pp. 133-144., 1999.

[11] M. A. Shahin, M. B. Jaksa, and H. R. Maier, "Artificial neural network applications in geotechnical engineering," Australian Geomechanics, pp. 49-62, 2001.

[12] A. W. C. Oreta and K. Kawashima, "Neural network modeling of confined compressive strength and strain of circular concrete columns," Journal of Structural Engineering, vol. 129, no. 4, pp. 554-561, 2003.

[13] M. B. Jaksa, H. R. Maier, and M. A. Shahin, "Future challenges for artificial neural network modelling in engineering," in Proceedings of the 12th International Conference of International Association for Computer Methods and Advances in Geomechanics (IACMAG '08), pp. 1710-1719, 2008.
[14] Z. Waszczyszyn, "Artificial neural networks in civil and structural engineering: ten years of research in Poland," Computer Assisted Mechanics and Engineering Sciences, vol. 13, no. 4, pp. 489-512, 2006.

[15] H. Adeli, "Neural networks in civil engineering: 1989-2000," Computer-Aided Civil and Infrastructure Engineering, vol. 16, no. 2, pp. 126-142, 2001.

[16] H. G. Ni and J. Z. Wang, "Prediction of compressive strength of concrete by neural networks," Cement and Concrete Research, vol. 30, no. 8, pp. 1245-1250, 2000.

[17] M. Saridemir, "Prediction of compressive strength of concretes containing metakaolin and silica fume by artificial neural networks," Advances in Engineering Software, vol. 40, no. 5, pp. 350-355, 2009.

[18] M. A. Sayed, "Statistical modeling and prediction of compressive strength of concrete," Concrete Research Letters, vol. 3, no. 2, pp. 452-458, 2012.

[19] K. W. Day, Concrete Mix Design, Quality Control and Specification, E \& FN Spon, London, UK, 2nd edition, 1992.

[20] British Standard Institution, "BS, 1881: part 1. Method for making test cubes from fresh concrete," London, UK, 1983.

[21] British Standards Institution, "BS 1881: part 111. Method of normal curing of test specimens (20_C method)," London, UK, 1983.

[22] British Standards Institution, "BS, 1881: part 116. Method for determination of compressive strength of concrete cubes," London, UK, 1983. 

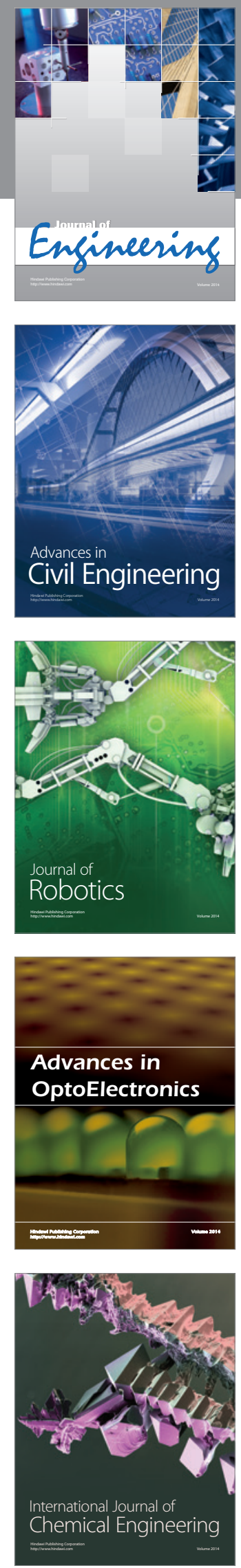

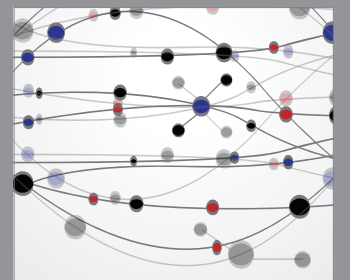

The Scientific World Journal
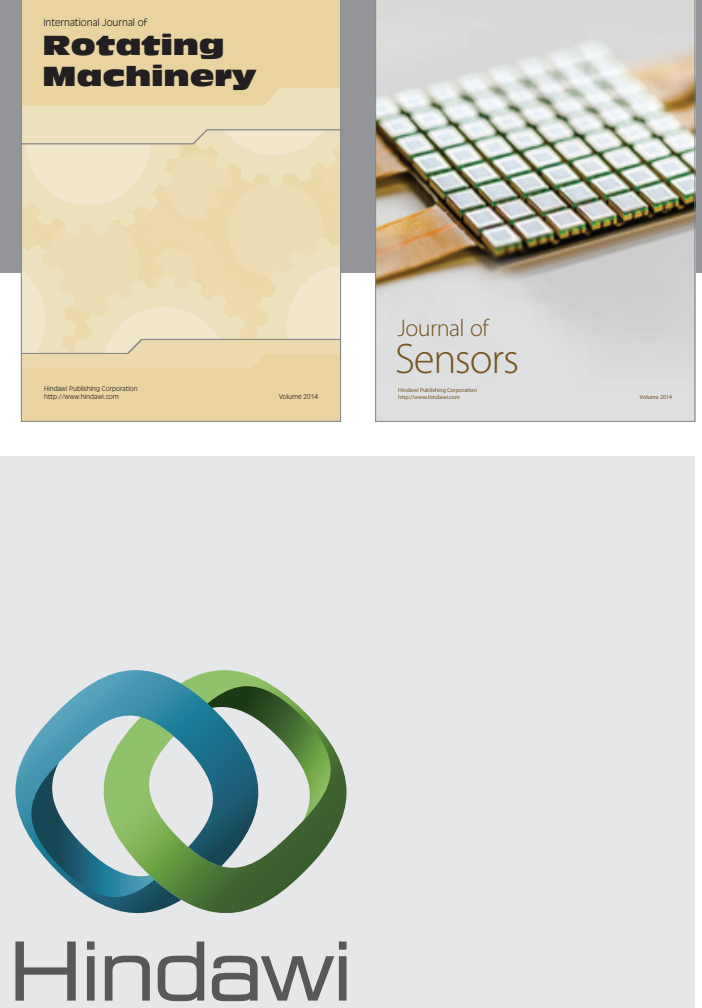

Submit your manuscripts at http://www.hindawi.com
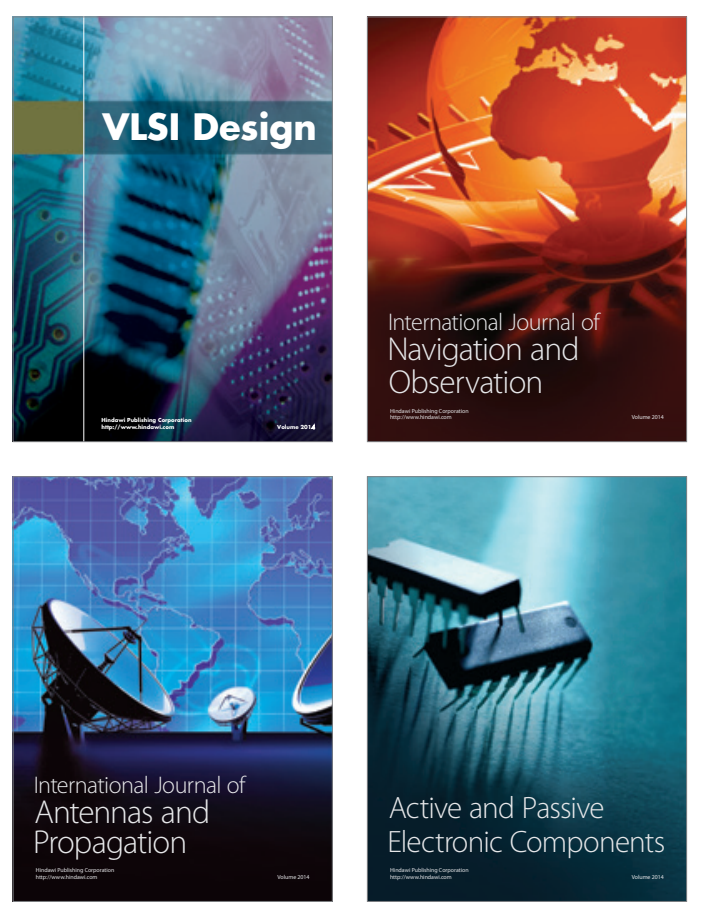
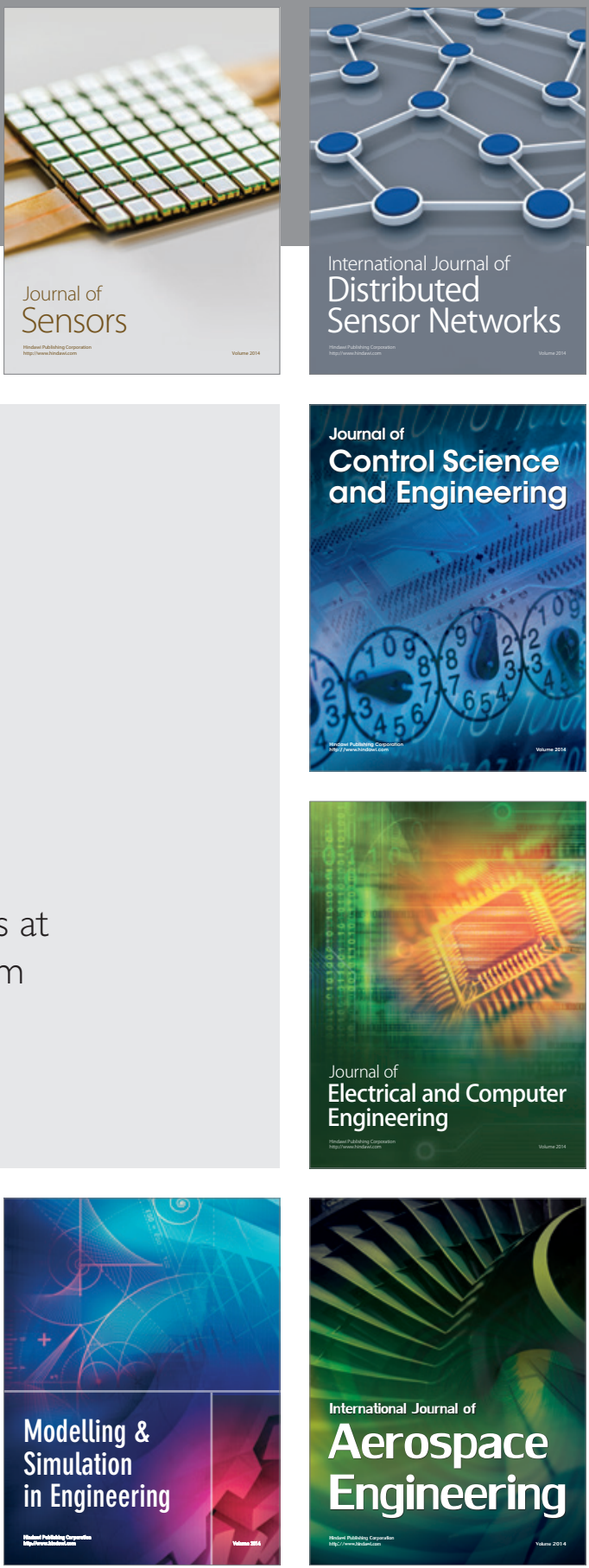

Journal of

Control Science

and Engineering
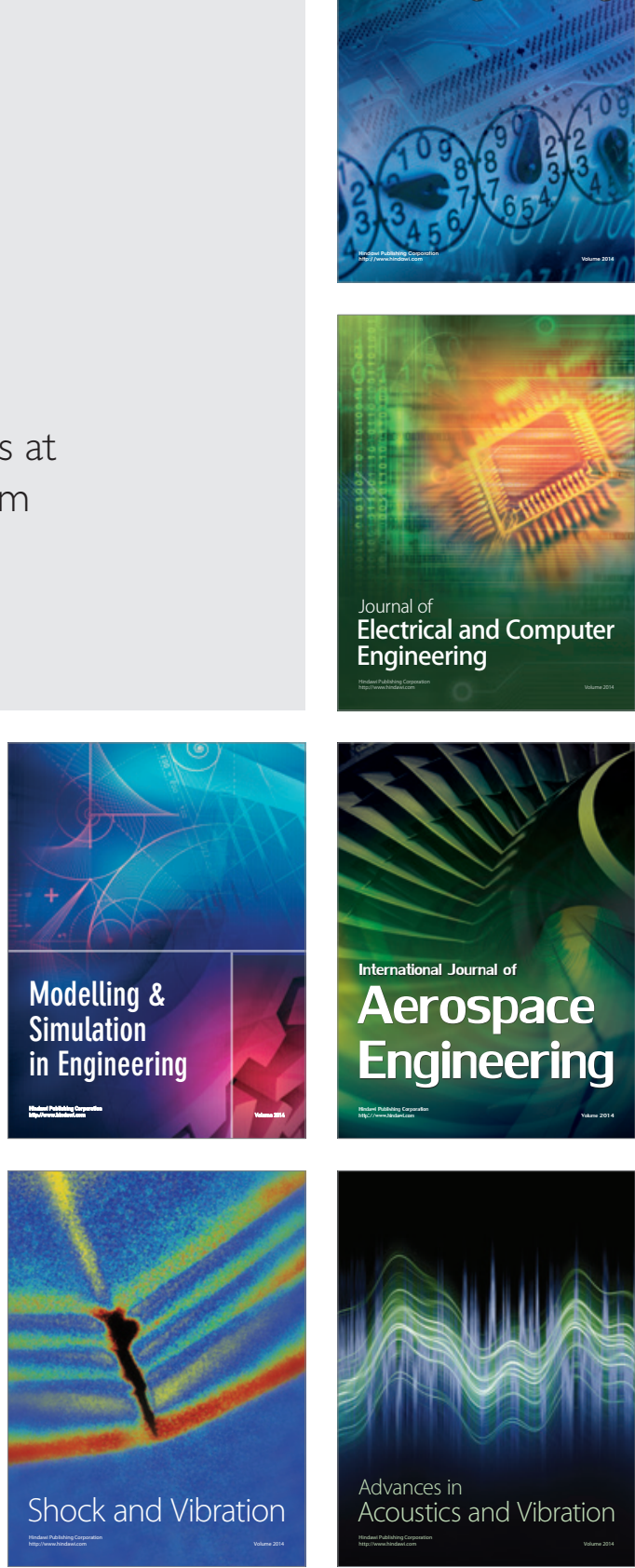